\title{
The World Health Organization's Essential Diagnostics List
}

\section{Diagnostics for neurologic disorders}

Greer Waldrop, MD, Teddy G. Goetz, MS, Omar K. Siddiqi, MD, Igor J. Koralnik, MD, Hiral Shah, MD, and
Kiran T. Thakur, MD

Neurology ${ }^{\circledR}$ 2019;93:680-683. doi:10.1212/WNL.0000000000008247

On the recommendation of the WHO Expert Committee on the Selection and Use of Essential Medicines in 2017, the inaugural WHO Essential Diagnostics List (EDL) was published by the WHO's Strategic Advisory Group of Experts on In-Vitro Diagnostics in May 2018. ${ }^{1}$ The EDL seeks to improve global treatment by providing "a catalogue of tests needed to diagnose both the most common conditions worldwide and diseases of global importance in both primary care and advanced settings." ${ }^{\prime, 2}$ This first iteration of the EDL includes diagnostic tests enabling the use of medications on the WHO Essential Medicines List (EML), which has guided international policies and funding decisions for the last 4 decades. ${ }^{3}$ Yet there is little representation of neurologic treatments on the EML, including a lack of medications for dementia, multiple sclerosis, neuropathic pain, and movement disorders, as well as commonly used medications for migraine such as triptans (table). ${ }^{4}$

By failing to account for disorders that already lack coverage in the EML, the EDL exacerbates existing categorical oversights for neurologic disorders. ${ }^{4-6}$ Of the 113 diagnostics tests included in the first edition of the EDL, only 3 explicitly pertain to neurologic diseases: the CSF cryptococcal antigen test for diagnosis of cryptococcal meningitis, the CSF nucleic acid amplification test for diagnosis of CNS tuberculosis, and CSF bacterial culture. This lack of emphasis on neurologic disorders, particularly noncommunicable diseases, constitutes an important oversight as globally, neurologic disorders account for the largest group-cause of disability-adjusted life-years, collectively contributing $10.2 \%{ }^{7}$ Further, death from neurologic disorders has increased $37 \%$ since estimates in 2000 . $^{7}$

Here, we identify 2 neurologic diagnostic tools not included in the EDL, basic CSF analysis and head CT, to highlight the opportunities and challenges associated with integration of diagnostics for neurologic disorders, particularly in resource-limited settings. We choose to discuss basic CSF studies as they represent a testing modality that could be more readily incorporated into the EDL and perhaps a resource-limited setting, while head CT scan represents a diagnostic modality requiring an extensive comprehensive approach to operationalize. Both showcase the limitations of the EDL in isolation, and the importance of constructing diagnostics around a framework for implementation.

\section{CSF analysis}

The 3 neurologic diagnostics included in the EDL involve analyzing CSF, though missing from the EDL are basic CSF studies used routinely in clinical practice (CSF white blood cells [WBCs], red blood cells $[\mathrm{RBC}]$, protein, and glucose). The EDL includes quantification of WBC and RBC in capillary blood and venous blood with manual microscopy of peripheral smear and hematology analyzer. Manual microscopy of wet prep smear remains a classical and accurate way of

\author{
Correspondence \\ Dr. Thakur
}

ktt2115@cumc.columbia.edu

MORE ONLINE

\section{ค Podcast}

Dr. Gregory Day talks with Dr. Kiran Thakur and Dr. Greer Waldrop about the challenges and implications of the new Essential Diagnostics List issued by the World Health Organization. NPub.org/lv61t7

\footnotetext{
From the Department of Neurology (G.W., H.S., K.T.T.), Community and Global Neurology Program, Columbia University Irving Medical Center; Vagelos College of Physicians and Surgeons (T.G.G.), Columbia University, New York; Department of Neurology, Global Neurology Program (O.K.S.) and Department of Internal Medicine, Center for Vaccines and Virology Research (O.K.S.), Beth Israel Deaconess Medical Center, Boston, MA; Department of Internal Medicine (O.K.S.), University of Zambia School of Medicine, Lusaka; and Department of Neurological Sciences (I.J.K.), Rush University Medical Center, Chicago, IL.

Go to Neurology.org/N for full disclosures. Funding information and disclosures deemed relevant by the authors, if any, are provided at the end of the article.
} 


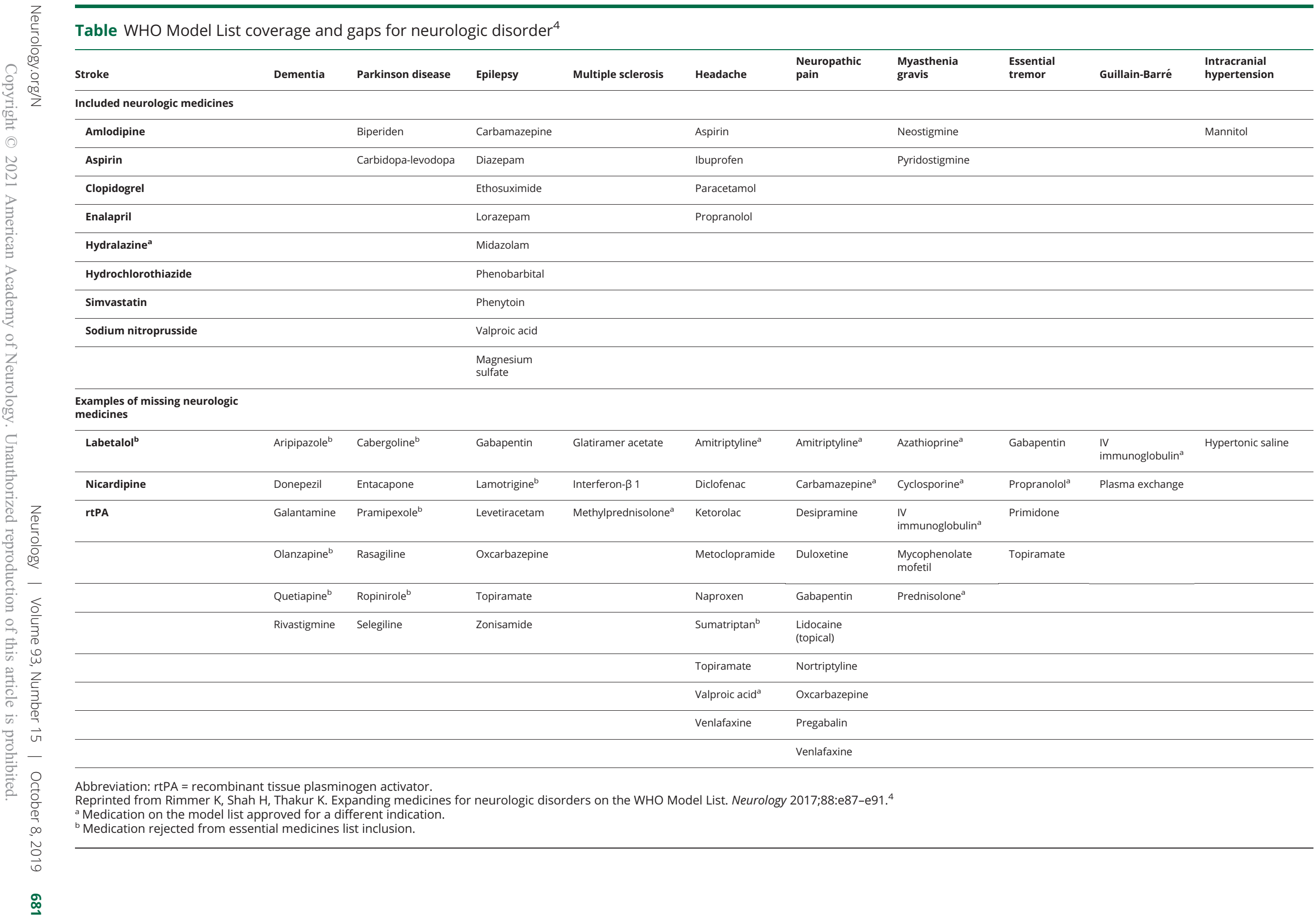


quantifying cells within CSF already validated in the resourcelimited setting. ${ }^{8,9}$ Similarly, the EDL already includes quantification of glucose and protein (lipids, albumin) in capillary and venous blood with automated analyzers, which also have been validated for use with CSF specimens. ${ }^{10}$ The addition of basic CSF studies to the EDL is essential to rule in or out neurologic infections as well as other conditions including inflammatory conditions such as Guillain-Barré syndrome.

While we believe that the inclusion of CSF basic studies is essential, we must also consider what a region would require to implement CSF studies including lumbar puncture (LP) kits, training of personnel to perform the procedure safely, and accessible, functional laboratory tests and equipment. Beyond the operational logistics of CSF acquisition, there remains a strong cultural stigma to LP in some regions, which requires further consideration. ${ }^{11}$ Thus, critical implementation challenges and research gaps remain at the operational level not only for the CSF-based assays already in the EDL, but also for the adoption of new CSF-based assays.

\section{Head CT scan}

Head CT scan has the potential to benefit the most prevalent global neurologic diseases including acute cerebrovascular accidents, which is now the second leading cause of death worldwide, but requires important multidisciplinary coordination for implementation. ${ }^{12}$ One could argue its incorporation into the EDL, as noncontrast head CT scan is a fast and effective way to both diagnose and rule out acute intracerebral hemorrhage, brain abscess, or tumor, and to guide treatment. Yet access to CT scans differs widely, with the African region having on average $0.4 \mathrm{CT}$ scanners per 1 million population and the South Asian region 3.1 CT scanners per 1 million population. ${ }^{13}$ One must balance the potential utility of placing head CT on an EDL with the realities of the operational systems required to effectively use the CT scan to guide patient care. One must consider access to the machine, routine maintenance, adequately trained technicians, electricity required, physicians trained in image interpretation, and a health system (i.e., transport, coordination) to facilitate the scan quickly so that subsequent treatments can be implemented (figure).

Although the scope of integrating tissue plasminogen activator (tPA) in the global context remains beyond the scope of this article, the discussion of the diagnosis of acute stroke would be remiss without the inclusion of the known, effective therapies. Consequently, in addition to prioritizing CT scan as an essential diagnostic, one must consider how to implement an integrated system that includes access to medications for lowering blood pressure, the ability to monitor patients in a critical care setting, access to aspirin and tPA, and the trained personnel to give tPA within a time window for efficacy. These downstream steps are challenging in a resource-limited setting, and are fundamental to consider in conceptualizing and developing a global EDL.

\section{Toward expanded neurologic diagnostics}

An increase in the diagnostic tests and devices on the EDL for neurologic disorders is critical. There are fundamental

Figure Multifactorial determinations for the utility of head CT scan in evaluating stroke in resource-limited settings

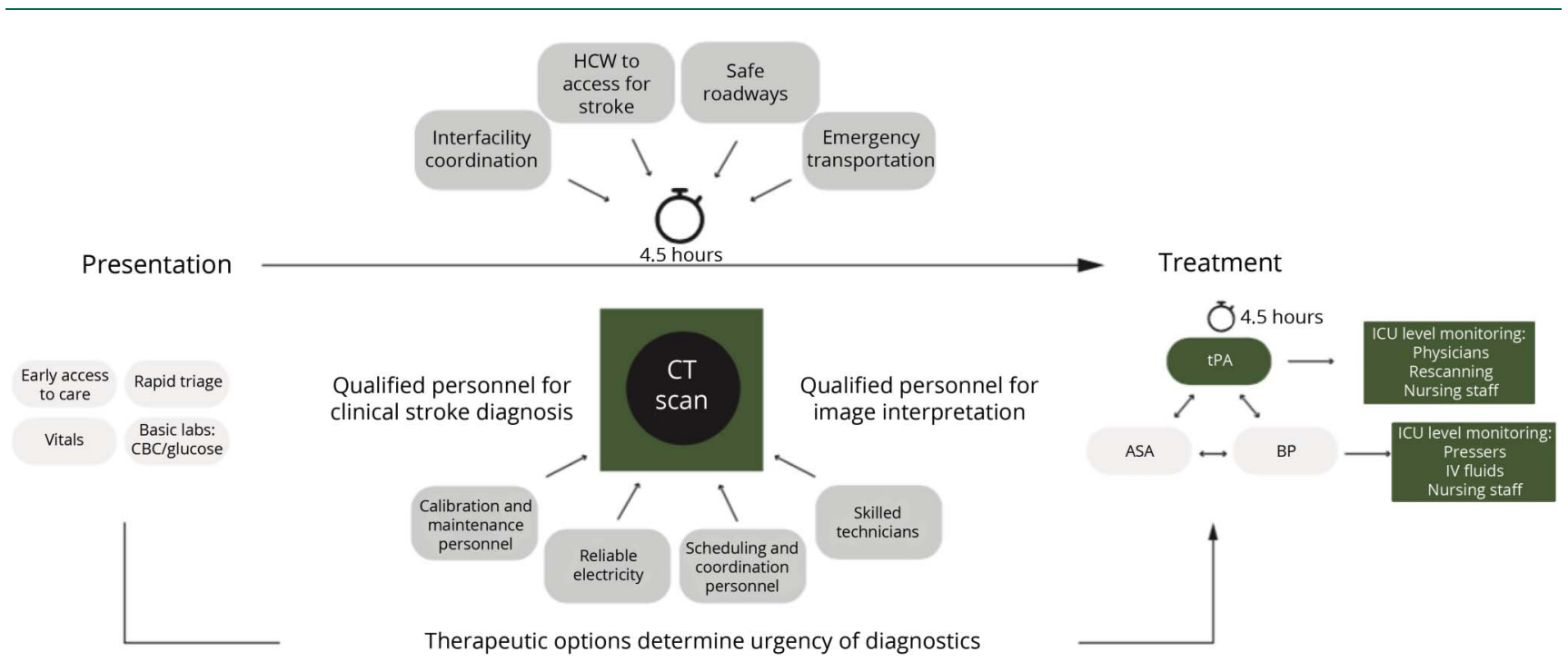

Cost concern at the health system and personal leve

ASA = acetylsalicylic acid; $\mathrm{BP}$ = blood pressure; $\mathrm{CBC}$ = complete blood count; $\mathrm{HCW}$ = health care worker; ICU = intensive care unit; tPA = tissue plasminogen activator. 
neurodiagnostics including basic CSF studies and head CT, EMG/nerve conduction studies, and EEG absent in the EDL. Simply identifying essential diagnostics in the EDL is inadequate without contextualizing the necessary components needed for appropriate utilization of diagnostic tests, specifically in resource-limited settings. A more comprehensive approach that identifies essential diagnostics alongside necessary implementation steps may serve as a better model for approaching global diagnostics. ${ }^{14}$ This approach should include strategies to integrate diagnostics into current health care systems and identifying limitations in resource-limited settings. Ultimately, moving toward an approach that accounts for the complexities of implementation of diagnostic testing in varied health care settings may better promote the goals of equitable and universal health care coverage.

\section{Update}

In July 2019, the 2nd Edition of the WHO's EDL was released. Included in the second edition are 2 additional neurodiagnostic tests: CSF venereal disease research laboratory (VDRL) testing for neurosyphilis and CSF cell cytology. Despite the increased representation of neurologic disease in the second edition of the EDL, routine neurodiagnostics remain absent. The additional tests further emphasize the need for inclusion of the basic CSF profile (CSF WBC, RBC, glucose and protein) to the list, as the interpretation of CSF VRDL and cytology results without a basic CSF profile remains limited.

\section{Author contributions}

G. Waldrop: drafting/revising the manuscript, data acquisition, study concept or design, analysis or interpretation of data, accepts responsibility for conduct of research and final approval. T.G. Goetz: drafting/revising the manuscript, data acquisition, study concept or design, analysis or interpretation of data, accepts responsibility for conduct of research and final approval, acquisition of data, statistical analysis. O.K. Siddiqi: drafting/revising the manuscript, accepts responsibility for conduct of research and final approval. I.J. Koralnik: drafting/ revising the manuscript, analysis or interpretation of data, accepts responsibility for conduct of research and final approval. H. Shah: drafting/revising the manuscript, accepts responsibility for conduct of research and final approval. $\mathrm{K}$. Thakur: drafting/revising the manuscript, study concept or design, accepts responsibility for conduct of research and final approval.

\section{Acknowledgment}

The authors thank Sarah Torres for review of the final version of this manuscript.

\section{Study funding}

No targeted funding reported.

\section{Disclosure}

G. Waldrop, T. Goetz, O. Siddiqi, and I. Koralnik report no disclosures relevant to the manuscript. H. Shah: external consultant for the WHO. K. Thakur: external consultant for the WHO. Go to Neurology.org/N for full disclosures.

\section{References}

1. First-ever WHO List of Essential Diagnostic Tests to Improve Diagnosis and Treatment Outcomes. Geneva: The World Health Organization; 2018.

2. Model List of Essential in Vitro Diagnostics. Geneva: World Health Organization; 2018.

3. Schroeder LF, Guarner J, Elbireer A, Castle PE, Amukele TK. Time for a model list of essential diagnostics. N Engl J Med 2016;374:2511-2514.

4. Rimmer K, Shah $\mathrm{H}$, Thakur K. Expanding medicines for neurologic disorders on the WHO Model List. Neurology 2017;88:e87-e91.

5. McLane H, Berkowitz A, Wolper E, Mckenzie E, et al. Global cost and availability of neuro diagnostic tests: a survey-based analysis. Neurology 2015;84(14 suppl): S37.004.

6. McLane HC, Berkowitz AL, Patenaude BN, et al. Availability, accessibility, and af fordability of neurodiagnostic tests in 37 countries. Neurology 2015;85:1614-1622.

7. Feigin VL, Abajobir AA, Abate KH, et al. Global, regional, and national burden of neurological disorders during 1990-2015: a systematic analysis for the Global Burden of Disease Study 2015. Lancet Neurol 2017;16:877-897.

8. Tanada H, Ikemoto T, Masutani R, Takubo T. Evaluation of the automated hematology analyzer ADVIA ${ }^{\circ} 120$ for cerebrospinal fluid analysis and usage of unique hemolysis reagent. Int J Lab Hematol 2014;36:83-91.

9. Sandhaus LM, Dillman C, Hinkle W, et al. A new automated technology for cerebrospinal fluid cell counts: comparison of accuracy and clinical impact of GloCyte, sysmex XN, and manual methods. Am J Clin Pathol 2017;147:507-514.

10. Lefrere B, Plantamura J, Renard C, et al. Biochemical analysis of cerebrospinal fluid in the laboratories of deployed medical treatment facilities: are Multistix 10 SG strip and iSTAT useful? J R Army Med Corps 2017;163:397-400.

11. Thakur KT. Kondwelani M, Lottie H, et al, Lumbar puncture refusal in sub-Saharan Africa: a call for further understanding and intervention. Neurology 2015;84: 1988-1990.

12. Global Health Estimates 2016: Deaths by Cause, Age, Sex, by Country And by Region, 2000-2016. Geneva: World Health Organization; 2018.

13. Global Atlas of Medical Devices. Geneva: World Health Organization; 2017.

14. WHO List of Priority Medical Devices for Cancer Management. Geneva: The World Health Organization; 2017.

\section{Subspecialty Alerts by E-mail!}

Customize your online journal experience by signing up for e-mail alerts related to your subspecialty or area of interest. Access this free service by clicking on the "My Alerts" link on the home page. An extensive list of subspecialties, methods, and study design choices will be available for you to choose from-allowing you priority alerts to cutting-edge research in your field! 


\section{Neurology}

The World Health Organization's Essential Diagnostics List: Diagnostics for neurologic disorders

Greer Waldrop, Teddy G. Goetz, Omar K. Siddiqi, et al.

Neurology 2019;93;680-683

DOI 10.1212/WNL.0000000000008247

This information is current as of October 7, 2019

Updated Information \&

Services

References

Citations

Permissions \& Licensing

Reprints including high resolution figures, can be found at: http://n.neurology.org/content/93/15/680.full

This article cites 9 articles, 4 of which you can access for free at: http://n.neurology.org/content/93/15/680.full\#ref-list-1

This article has been cited by 1 HighWire-hosted articles: http://n.neurology.org/content/93/15/680.full\#\#otherarticles

Information about reproducing this article in parts (figures,tables) or in its entirety can be found online at:

http://www.neurology.org/about/about_the_journal\#permissions

Information about ordering reprints can be found online:

http://n.neurology.org/subscribers/advertise

Neurology $®$ is the official journal of the American Academy of Neurology. Published continuously since 1951, it is now a weekly with 48 issues per year. Copyright (C 2019 American Academy of Neurology. All rights reserved. Print ISSN:

0028-3878. Online ISSN: 1526-632X.

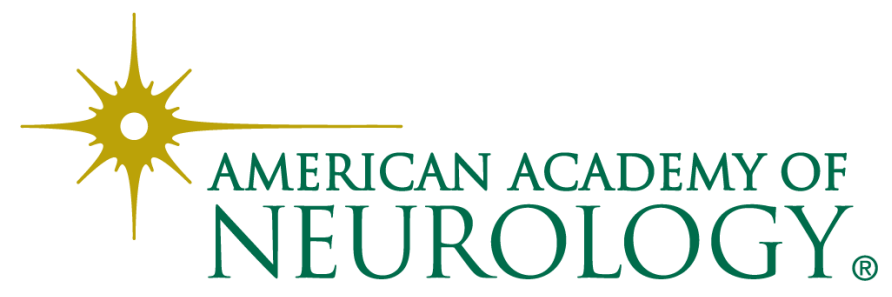

